\title{
PENETAPAN KADAR PSEUDOEPHEDRINE HCI, GUAIFENESIN DAN TRIPROLIDINE HCI SECARA SIMULTAN DALAM SEDIAAN SIRUP DENGAN METODE KCKT
}

\author{
Ana Adriyani, Yusnita Rifai, Risfah Yulianty \\ Fakultas Farmasi, Universitas Hasanuddin, Makassar
}

Kata Kunci :

Pseudoefedrin $\mathrm{HCl}$, Guafenisin, Triprolidine $\mathrm{HCl}, \mathrm{KCKT}$

\begin{abstract}
ABSTRAK
Dalam rangka mengontrol kualitas dan keamanan obat yang beredar, maka diperlukan metode analisis obat baru. Penelitian ini bertujuan untuk memperoleh metode analisis penetapan kadar campuran triprolidin $\mathrm{HCl}$, pseudoephedrine $\mathrm{HCl}$ dan guaifenesin dalam sediaan sirup secara simultan dengan metode KCKT. Kondisi analisis KCKT menggunakan kolom C18. [Waters x bridge $(4,6$ x $250 \mathrm{~mm}) 5 \mu \mathrm{m}$ ], pada panjang gelombang $210 \mathrm{~nm}$, kecepatan alir 0,6 ml/menit dengan fase gerak : [methanol : dapar KH2PO4 pH 3,0 (45 : 55)]. Hasil uji presisi (n=10) mempunyai kadar rata-rata dan \%RSD untuk pseudoephedrine $\mathrm{HCl}$, guaifenesin dan triprolidine masing masing sebesar 5,86 $\mathrm{mg} / \mathrm{mL}(97,71 \%)$ dan $0,44 \% ; 20,19 \mathrm{mg} / \mathrm{mL}(100,95 \%)$ dan $0.37 \% ; 0,26 \mathrm{mg} / \mathrm{mL}(103,25 \%)$ dan $1,02 \%$ dari jumlah yang tertera pada etiket. Hasil uji akurasi berdasarkan nilai recovery untuk pseudoephedrine $\mathrm{HCl}$, guaifenesin dan triprolidine mempunyai rentang masing masing 100,74 - 103,67\%; 97,03 - 101,33\%; 97,03 - 101,73\% . Persyaratan recovery yang dapat menjamin hasil uji untuk pseudoephedrine $\mathrm{HCl}$ antara 95,0 -105,0\% untuk guaifenesine 97,0 - 103,0\% dan untuk triprolidin $\mathrm{HCl}$ 90,0 - 107,0\%. Berdasarkan hasil penelitian ini maka dapat dapat diperoleh metode analisis penetapan kadar pseudoephedrine $\mathrm{HCl}$, guaifenesin dan triprolidine $\mathrm{HCl}$ secara simultan dan dapat digunakan sebagai acuan dalam menganalisis sampel.
\end{abstract}

\section{PENDAHULUAN}

Semakin berkembangnya ilmu pengetahuan, obat yang beredar dimasyarakat semakin bervariasi, saat ini banyak dijumpai satu sediaan obat yang mengandung lebih dari satu jenis zat aktif. Adanya lebih dari satu macam zat aktif biasanya ditujukan untuk mendapatkan efek yang lebih baik, dimana kegunaan zat aktif yang satu mendukung kegunaan zat aktif yang lainnya. Pada umumnya, kombinasi obat harus dapat menghasilkan efek farmakologi yang diinginkan dan aman untuk digunakan. Oleh karena itu, perlu analisis penetapan kadar dalam sediaannya untuk menjamin ketepatan dosis tiap sediaan sehingga dapat menjamin efek farmakologis dan keamanan obat.

Obat batuk dan flu merupakan salah satu formulasi yang paling banyak beredar dan terdapat dalam banyak bentuk sediaan farmasi seperti bentuk sirup, suspensi, sachets, kapsul dan tablet (1). Salah satu sediaan farmasi yang mengandung lebih dari satu macam zat aktif adalah triprolidine $\mathrm{HCl}$, pseudoephedrine $\mathrm{HCl}$, guaifenesin dan tripolidine $\mathrm{HCl}$ membantu meringankan gejala yang penyebabnya secara keseluruhan maupun sebagian tergantung pada pelepasan histamine. Senyawa dari golongan pyrolidin ini bekerja sebagai antagonis kompetitif untuk reseptor histamine $\mathrm{H} 1$ dan mampu menekan sistim saraf pusat sehingga menyebabkan kantuk. Pseudoephedrine mempunyai aktivitas simpatomimetik langsung maupun tidak langsung dan merupakan dekongestan saluran nafas bagian atas. Guaifenesin memiliki kerja ekspektoran kerjanya menurunkan viskositas lendir dengan cara meningkatkan volume dan kandungan air dari sekresi tenggorokan dengan demikian membantu pengeluaran sputum. (2) Terkait dengan dosis yang dianjurkan, pada umumnya pabrik obat menetapkan formula obat multikomponen dengan proporsi kandungan zat aktif yang sangat berbeda. Hal inilah yang menyebabkan kesulitan pada penetapan kadar zat aktif dalam obat tersebut. Selain itu, perbedaan sifat fisika-kimia masing-masing zat aktif, salah satunya adalah polaritas, juga membuat obat multikomponen sulit ditetapkan kadarnya (3).

Metode Analisa merupakan bagian penting dalam pemeriksaan formulasi sediaan farmasi dalam hal kontrol kualitas dan keamanannya. Semakin tingginya produksi obat dalam industry farmasi baik itu di dalam dan di seluruh dunia mengakibatkan meningkatnya permintaan untuk mencari metode analisa baru dan sistematis di industri farmasi. Sebagai akibatnya, pengembangan metode analisa menjadi hal mendasar dalam analisis analisis. (4)

Dalam pustaka resmi metode analisa untuk Pseudoephedrine $\mathrm{HCl}$ dan Triprolidine $\mathrm{HCl}$ dalam sediaan sirup telah tersedia, begitu juga metode analisa untuk Guaiafenesin dalam sediaan sirup telah tersedia (5). Jika analisis zat aktif dilakukan secara terpisah akan diperlukan biaya yang banyak dan waktu yang lama oleh karena itu perlu dilakukan pengembangan metode analisa penetapan kadar Triprolidine $\mathrm{HCl}$, Pseudoephedrine $\mathrm{HCl}$, dan Guaifenesin dalam sediaan sirup secara simultan yang efektif dan memenuhi syarat parameter validasi.

Kromatografi Cair Kinerja Tinggi (KCKT) atau High Performance Liquid Chromatography (HPLC) adalah salah satu metode analisa yang dapat 
digunakan dalam control kualitas obat karena merupakan metode yang dapat menghasilkan pemisahan yang sangat efisien dan mempunyai sensitivitas deteksi yang tinggi. Kromatografi cair kinerja tinggi merupakan metode analisis yang paling akurat yang dapat digunakan untuk menentukan kestabilan suatu produk obat termasuk analisis kuantitatif maupun kualitatif produk obat (6).

Penelitian ini bertujuan untuk memperoleh metode untuk analisis penetapan kadar Tripolidine $\mathrm{HCl}$, Pseudoephedrine $\mathrm{HCl}$ dan Guaifenesin secara simultan dan untuk mengetahui apakah metode ini dapat digunakan untuk penetapan kadar pseudpephedrine $\mathrm{HCl}$, guaifenesin dan triprolidine $\mathrm{HCl}$ dalam sediaan sirup

\section{METODE PENELITIAN}

\section{Alat dan Bahan Penelitian}

Peralatan Seperangkat alat Kromatografi Cair Kinerja Tinggi dilengkapi detektor UV/VIS (Shimadzu LC 10 AD), Kolom oktadesilsilana (C18) panjang $250 \mathrm{~mm}$, diameter dalam 4,6 mm, ukuran partikel $5 \mu \mathrm{m}$. (Xbridge Waters), pH meter (Inolab 7110), Timbangan Analitik (Sartorius)

Bahan Sirup yang Tiap ml mengandung Triprolidin $\mathrm{HCl} \mathrm{0,25}$ $\mathrm{mg}$, Pseudoefedrin $\mathrm{HCl} 6 \mathrm{mg}$, dan Guaifenisin $20 \mathrm{mg}$, Baku Pembanding Pseudoefedrin HCl BPFI, Guaifenisin BPFI, Triprolidin $\mathrm{HCl}$ BPFI yang diperoleh dari laboratorium Bahan Baku Pembanding Pusat Pengujian Obat dan Makanan Nasional Badan POM RI, Pereaksi Metanol, Kalium dihidrogen fosfat, Asam ortofosfat.

\section{Teknik Analisis}

Untuk Presisi Jumlah Triprolidin $\mathrm{HCl}$, Pseudoefedrin $\mathrm{HCl}$ dan Guaifenisin per ml sirup dalam mg (W):

$$
\operatorname{Kadar}(m g)=\frac{L u}{L b} \times \frac{F u}{F b} \times \frac{B b}{B u} \times B j
$$

Kandungan Triprolidin $\mathrm{HCl}$, Pseudoefedrin $\mathrm{HCl}$ dan Guaifenisin per ml sirup dihitung terhadap jumlah yang tertera pada etiket $(\mathrm{K})$ :

$$
\operatorname{Kadar}(\%)=\frac{\operatorname{Kada}(\mathrm{mg})}{\operatorname{Ke}} \times 100 \%
$$

Keterangan:

$\mathrm{Lu}=$ luas puncak larutan uji

$\mathrm{Lb}=$ luas puncak larutan baku

$\mathrm{Bb}=$ bobot baku yang ditimbang

$\mathrm{Fu}=$ faktor pengenceran larutan uji

$\mathrm{Fb}=$ faktor pengenceran larutan baku

$\mathrm{Ke}=$ kadar triprolidin,pseudoefedrin dan guaifenasin per ml sirup yang tertera pada etiket.

Kriteria Keberterimaan simpangan Baku Relatif (RSD) yang diperoleh pada uji presisi tidak lebih dari $2 \%(5,18)$.

Untuk Akurasi Interprestasi hasil Perhitungan dilakukan seperti pada interpretasi hasil uji presisi.

$$
\begin{gathered}
\text { Kadar sampel }=\frac{\% \text { Kadar Presisi }}{100} \times \text { Ke } \times \frac{B}{B u} \\
\% \text { Recovery }=\frac{\text { Kadar Total }- \text { Kadar Sampel }}{\text { Baku yang ditambahkan }} \times 100
\end{gathered}
$$

Keterangan:

$\mathrm{Lu}=$ luas puncak larutan uji

$\mathrm{Lb}=$ luas puncak larutan baku

$\mathrm{Bb}=$ bobot baku yang ditimbang dalam

$\mathrm{Fu}=$ faktor pengenceran larutan uji

$\mathrm{Fb}=$ faktor pengenceran larutan baku

$\mathrm{Ke}=$ kadar Pseudoefedrin $\mathrm{HCl}$, Triprolidin $\mathrm{HCl}$ dan Guaifenisin per ml syrup yang tertera pada etiket dalam $\mathrm{mg}$

$\mathrm{Bu}=$ Bobot cuplikan dalam g

$\mathrm{N}=$ Jumlah syrup dalam larutan uji induk
Kriteria Keberterimaan (USP, 2016)

Hasil rata-rata rekoveri: Pseudoephedrine $\mathrm{HCl}$ 95,0-105,0\%. Guaifenesin 97,0-103,0 \%, Triprolidine HCl 90,0-107,0\%

\section{Prosedur Penelitian}

Uji Presisi dilakukan dengan membuat larutan Dapar 0,04 M pH 3,0 sebagai pelarut. Larutan Baku dengan konsentrasi Pseudoephedrine $\mathrm{HCl}$ : 0,06 mg/mL, baku Guaifenisin : 0,02 $\mathrm{mg} / \mathrm{mL}$ dan baku Triprolidine $\mathrm{HCl}: 0,0025 \mathrm{mg} / \mathrm{mL}$. Larutan Uji dengan konsentrasi yang sama dengan larutan baku dibuat dalam 10 replikasi. Selanjutnya dilakukan penetapan dengan Cara Pelarut, larutan baku, larutan uji masing-masing disuntikkan ke dalam Kromatografi Cair Kinerja Tinggi dengan kondisi sebagai berikut: Fase gerak Campuran metanol-Larutan dapar fosfat 0,04 M pH 3,0 (45:55). Kolom Panjang $250 \mathrm{~mm}$, diameter dalam 4,6 mm berisi L1 dengan ukuran partikel $5 \mu \mathrm{m}$ Laju Alir : 0,6 mL per menit Volume penyuntikan : 20 l. Detektor : UVVIS $210 \mathrm{~nm}$

Uji Akurasi (Recovery) dilakukan dengan metode penambahan baku (standard addition method) yaitu dengan menambahkan baku dengan konsentrasi tertentu $(80 \%$ sampai 120 \%). Cara Penetapan Dilakukan seperti cara penetapan pada uji presisi. Masing-masing konsentrasi larutan dilakukan penimbangan dan pengenceran sebanyak 3 kali $(7,9,13,15)$.

\section{HASIL DAN PEMBAHASAN}

Penelitian ini bertujuan untuk memperoleh metode untuk

\begin{tabular}{|c|c|c|c|c|c|c|}
\hline \multirow[b]{2}{*}{ No } & \multicolumn{2}{|c|}{$\begin{array}{l}\text { Pseudoephedrine } \\
\mathrm{HCl}\end{array}$} & \multicolumn{2}{|c|}{ Guaifenesin } & \multicolumn{2}{|c|}{ Triprolidine $\mathrm{HCl}$} \\
\hline & $\begin{array}{c}\text { Kadar } \\
\text { (mg) }\end{array}$ & $\begin{array}{c}\text { Kadar } \\
(\%)\end{array}$ & $\begin{array}{l}\text { Kadar } \\
\text { (mg) }\end{array}$ & $\begin{array}{c}\text { Kadar } \\
(\%)\end{array}$ & $\begin{array}{l}\text { Kadar } \\
\text { (mg) }\end{array}$ & $\begin{array}{c}\text { Kadar } \\
(\%)\end{array}$ \\
\hline 1 & 5,872 & 97,87 & 20,230 & 101,15 & 0.256 & 102,52 \\
\hline 2 & 5,884 & 98,06 & 20,255 & 101,28 & 0.258 & 103,02 \\
\hline 3 & 5,877 & 97,95 & 20,240 & 101,20 & 0.257 & 102,75 \\
\hline 4 & 5,883 & 98,05 & 20,241 & 101,21 & 0.257 & 102,75 \\
\hline 5 & 5,869 & 97,81 & 20,209 & 101,05 & 0.255 & 102,02 \\
\hline 6 & 5,859 & 97,64 & 20,166 & 100,83 & 0.256 & 102,47 \\
\hline 7 & 5,817 & 96,95 & 20,076 & 100,38 & 0.261 & 104,24 \\
\hline 8 & 5,817 & 96,94 & 20,049 & 100,24 & 0.263 & 105,34 \\
\hline 9 & 5,887 & 98,11 & 20,260 & 101,30 & 0.261 & 104,45 \\
\hline 10 & 5,860 & 97,66 & 20,172 & 100,86 & 0.257 & 102,99 \\
\hline 11 & 5,862 & 97,71 & 20,190 & 100,95 & 0,258 & 103,25 \\
\hline SD & 0,33 & 0,43 & 0,07 & 0,37 & 0,003 & 1,06 \\
\hline RSD & 0,44 & 0,44 & 0,37 & 0,37 & 1,02 & 1,02 \\
\hline
\end{tabular}
penetapan kadar pseudoephedrine $\mathrm{HCl}$, guaifenesin dan triprolidine $\mathrm{HCl}$ dalam sediaan sirup secara simultan dengan metode KCKT.

Uji presisi dilakukan untuk melihat ukuran yang menunjukkan derajat kesesuaian antara hasil uji individual, presisi diukur sebagai simpangan baku relative (7). Uji presisi dilakukan pada konsentrasi pseudoefedrin $\mathrm{HCl} 0,06 \mathrm{mg} / \mathrm{mL}$, guaifenesin $0,2 \mathrm{mg} / \mathrm{mL}$ dan triprolidin $\mathrm{HCl} 0,0025 \mathrm{mg} / \mathrm{ml}$ dengan 10 kali replikasi. Berdasarkan penelitian yang dilakukan diperoleh hasil RSD untuk pseudoefedrin $\mathrm{HCl}$ 0,44\%, Guaifenesin 0,37\% dan triprolidin $\mathrm{HCl} 1,02 \%$. Analisis presisi dilakukan dengan minimal 6 replikasi dan kriteria penerimaan RSD tidak lebih dari $2 \%$. Selain itu kandungan analit dalam sampel juga memenuhi syarat dimana syarat untuk pseudoephedrine HCL, guaifenesin dan triprolidine $\mathrm{HCl}$ masing masing 95,0-105,0\%, 90,0-110,0\%, dan 90,0$107,0 \%$.

Penentuan akurasi dilakukan untuk memastikan apakah metode ini menunjukkan derajat kedekatan antara hasil analisis dengan kadar analit sebenarnta. Uji akiurasi dilakukan dengan metode penambahan baku yaitu dengan menambahkan sejumlah analit dengan konsentrasi tertentu 
pada sampel yang diperiksa lalu dianalisis dengan metode yang akan divalidasi. Uji akurasi dilakukan pada tiga tingkat konsentrasi yang berbeda yaitu $80 \%, 100 \%$ dan 120\% dengan replikasi masing masing tiga kali.

\begin{tabular}{|c|c|c|c|}
\hline No & $\begin{array}{c}\text { Konsentrasi } \\
(\%)\end{array}$ & Rekoveri (\%) & Rekoveri rata-rata (\%) \\
\hline \multirow{3}{*}{1} & 80 & 101,88 & \\
\hline & 80 & 101,83 & 101,75 \\
\hline & 80 & 101,54 & \\
\hline \multirow{3}{*}{2} & 100 & 100,74 & \\
\hline & 100 & 101,07 & 101,55 \\
\hline & 100 & 102,84 & \\
\hline \multirow{3}{*}{3} & 120 & 103,89 & \\
\hline & 120 & 102,28 & 102,80 \\
\hline & 120 & 102,23 & \\
\hline & Rata-rata & & 102,03 \\
\hline
\end{tabular}

\begin{tabular}{|c|c|c|c|}
\hline No & $\begin{array}{c}\text { Konsentrasi } \\
(\%)\end{array}$ & Rekoveri (\%) & Rekoveri rata-rata (\%) \\
\hline \multirow{3}{*}{1} & 80 & 101,22 & \multirow{3}{*}{101,29} \\
\hline & 80 & 101,33 & \\
\hline & 80 & 101,32 & \\
\hline \multirow{3}{*}{2} & 100 & 98,09 & \multirow{3}{*}{99,12} \\
\hline & 100 & 98,79 & \\
\hline & 100 & 100,49 & \\
\hline \multirow{3}{*}{3} & 120 & 97,03 & \multirow{3}{*}{97,31} \\
\hline & 120 & 97,45 & \\
\hline & 120 & 97,44 & \\
\hline & Rata-rata & & 99,24 \\
\hline
\end{tabular}

\begin{tabular}{cccc}
\multicolumn{4}{l}{ Tabel 4. Hasil Uji Akurasi Triprolidin $\mathrm{HCl}$} \\
\hline \multirow{2}{*}{ No } & $\begin{array}{c}\text { Konsentrasi } \\
\text { (\%) }\end{array}$ & Rekoveri (\%) & Rekoveri rata-rata (\%) \\
\hline \multirow{2}{*}{1} & 80 & 98,56 & \\
& 80 & 97,03 & 97,81 \\
\hline \multirow{2}{*}{2} & 80 & 97,83 & \\
& 100 & 99,31 & 100,67 \\
\hline \multirow{2}{*}{3} & 100 & 101,73 & \\
& 100 & 100,97 & 99,54 \\
\hline \multicolumn{5}{c}{120} & 99,18 & \\
\hline
\end{tabular}

Dari data uji akurasi diperoleh rentang perolehan kembali untuk pseudoefedrin HCl 100,74-103,67\%; guaifenesin 97,03-101,33\% dan tripeolidin $\mathrm{HCl}$ 97,03-101,73\%. Berdasarkan hasil perolehan kembali maka persyaratan akurasi terpenuhi dimana menurut USP rentang akurasi untuk pseudoefedrin $\mathrm{HCl}$ 95\%-105\% untuk guaifenesin 97,0103,0\% dan triprolidin $\mathrm{HCl}$ 90\%-107\%.

\section{KESIMPULAN}

Berdasarkan hasil penetapan metode analisis yang telah dilakukan pada penelitian ini dapat disimpulkan bahwa metode KCKT yang diperoleh dapat digunakan untuk analisa penetapan kadar pseudoephedrine $\mathrm{HCl}$, guaifenesin dan triprolidin $\mathrm{HCl}$ dalam sedian sirup secara simultan. Metode analisis yang diperoleh dalam penelitian ini dapat digunakan untuk penetapan kadar pseudoefedrin,guaifenesin dan triprolidin dalam sedian sirup obat flu.

\section{UCAPAN TERIMA KASIH}

Penulis mengucapkan terima kasih kepada Badan POM RI atas bantuan pendanaan. Penulis juga berterima kasih kepada Fakultas Farmasi Universitas Hasanuddin atas dukungan moril dan sarana selama penulis melakukan penelitian.

\section{DAFTAR PUSTAKA}

1. Hatic, C., Ebru Buyuktuncel, 2014. HPLC Method Development and Validation : Simultaneous Determination of Active Ingredients in Cough and Cold Pharmaceuticals. International Journal of Pharmacy and Pharmaceutical Sciences. 6(10);421-428

2. Ikatan Apoteker Indonesia, 2017. Informasi Spesialite Obat Indonesia ISSN 854-4492

3. Yolanda,M. 2015. Validasi metode Analisis Pseudoefedrin $\mathrm{HCl}$ Guaifenesin dan Deksklorfeniramin Maleate dalam Obat Flu dengan Kromatografi Cair Kinerja Tinggi Pasangan Ion. Tesis tidak diterbitkan. Yogyakarta: Program Pasca Sarjana Fakultas Farmasi UGM

4. Ravisankar, P., Navya, N,CH., Pravallika, D., Sri,N., 2015. A Review on Stepby Step Analytical Method Validation. IOSR Journal of Pharmacy. 5(10) $07-19$

5. United States Pharmacopeial Convention. 2016. The United States Pharmacopeia, 39th ed. United States Pharmacopeial Convention Inc, Twinbrook Parkway, Rockville

6. Bhardwaj, K.S., Dwivedia ., Agarwala,D.D. 2015, A Review : HPLC Method Development and Validation, International Journal pf Analytical and Bioanalytical Chemistry. 5(4):76-81

7. Harmita. 2004. Petunjuk Pelaksanaan Validasi Metode dan Cara Perhitungannya, Majalah Ilmu Kefarmasian. 1(3); 117 - 135.

8. Gandjar,I.G., and Rohman,A., 2018. Kimia Farmasi Analisis. Yogyakarta: Pustaka Pelajar, hal.323-417

9. Huber, L. 2003. Pharmaceutical Process Validation, 3rded. New York, Marcel Dekker:12

10. Kasuzaki, M., Ueda, S., Takeouchi, N., Ohgami, Y., 2012. Validation of analytical procedures by high-performance liquid chromatography for pharmaceutical analysis. Chromatography. 33 (2) 65-73

11. Kaushal,C. and Serivastava,B., 2010, A process of method development : A chromatographic approach. Journal of Chemical and Pharmaceutical Research. 2(2): 519-545

12. Kazakevich, Y. and Lobrutto, R., 2007, HPLC for Pharmaceutical Scientists, Wiley- Interscience A John Wiley \& Sons, INC., Publication, United States of America, pp. 94-101

13. Komite Akreditasi Nasional. 2008. SNI ISO/IEC 17025 (Versi Bahasa Indonesia) Persyaratan Umum Kompetensi Laboratorium Kalibrasi dan Pengujian. Jakarta: Badan Standarisasi Nasional.

14. Malviya, R., Bansal, V., Pal, O.P., Sharma, P. K., 2010. High Performance Liquid Chromatography : a Short Review. Jornal of Global Pharma Technolog. 2(5):22-26

15. Riyanto, 2014, Validasi dan Verifikasi Metode Uji Sesuai Dengan ISO/IEC 17025 Laboratorium Pengujian dan Kalibrasi. Edisi I, Penerbit Deeppublish CV Budi Utama. Yogyakarta.

16. Thammana, M. 2016. A Review on High Performance Liquid Chromatography (HPLC). RRJPA. 5(2) 22-28

17. Weetman,S.C. 2009. The Martindale, The Complete Drug Refference, 36th edition. 2009. Pharmaceutical Press

18. Yuwono,M.,Indrayanto,G.,2005. Validation of Chromatographic Method of Analysis. Profile of Drug Substance, Excipients, and Related Methodology, Vol.32,p.243-259 